\title{
Quantification of External Surface and Pore Mouth Acid Sites in Unit-Cell Thick Pillared MFI and Pillared MWW Zeolites
}

Yiqing Wu, Laleh Emdadi, Dongchang Qin, Junyan Zhang and Dongxia Liu*

Department of Chemical and Biomolecular Engineering, University of Maryland, College Park,

MD, 20742, USA

*Corresponding author:

Prof. Dongxia Liu

Email: liud@umd.edu

Phone: (+1) 301-405-3522

Fax: (+1) 301-405-0523

(C) 2016. This manuscript version is made available under the Elsevier user license http://www.elsevier.com/open-access/userlicense/1.0/ 
Abstract: The pillared MWW (PMWW or MCM-36) and pillared MFI (PMFI) zeolites consist of a single- or near single-unit-cell thick two-dimensional (2D) zeolitic layer structure. The concentrations of external surface and pore mouth Brønsted acid sites in these zeolites were quantified by a combined dimethyl ether (DME) titration and methanol dehydration in the presence of 2,6-di-tert-butylpyridine (DTBP) or triphenylphosphine (TPP), respectively. DME can access to all Brønsted acid sites in PMFI and PMWW zeolites and thus determine the total number of acid sites. DTBP cannot access to acid sites in micropores, but on the external surface and at the pore mouth regions. In contrast, TPP can only access to acid sites on external surface. The degree of decrease in methanol dehydration rate in the presence of DTBP or TPP indicates the fraction of the sum of external surface and pore mouth acid sites and the sole fraction of external surface acid sites, respectively. The study shows that PMFI contains $\sim 32 \%$ external surface and $\sim 6 \%$ pore mouth acid sites, while PMWW consists of $\sim 33 \%$ external surface and $\sim 31 \%$ pore mouth acid sites. The individual external surface or pore mouth acid site performed distinctively in alkylation of mesitylene by benzyl alcohol reactions.

Keywords: Pore mouth acid sites; External surface acid sites; Pillared zeolite; 2D zeolite structure; Organic base titration. 


\section{Introduction}

Zeolites are three-dimensional (3D) crystalline aluminosilicates with well-defined angstrom-size micropores and strong acidity, which are widely used as heterogeneous catalysts in petrochemical and fine chemical syntheses [1-5]. The acidity of zeolites originates from the substitution of tetrahedral $\mathrm{Si}$ atoms by $\mathrm{Al}$ atoms to form the $\mathrm{Al}-\mathrm{O}(\mathrm{H})-\mathrm{Si}$ sites in the framework, where a proton is attached to an oxygen atom that bridges tetrahedrally coordinated $\mathrm{Si}$ and $\mathrm{Al}$ atoms. The encapsulation of $\mathrm{Al}-\mathrm{O}(\mathrm{H})-\mathrm{Si}$ acid sites in micropores enables unique shape-selectivity in zeolite catalysis. The relatively small sizes of micropores, on the other hand, render low catalyst utilization due to limited access to and slow mass transport to/from the acid sites in zeolites when the processing of bulky molecules is concerned [6-9].

An approach to increase the acid site accessibility, mass transport and thus catalyst utilization is to slice 3D zeolites into nearly unit-cell thick ( 2-3 nm) 2D structures [10-17], in which the acid sites are exposed directly on the external surface or caged within a singlemicropore distance from the surface. In the catalytic processes, the bulky molecules can react over the acid sites on the external surface (external surface acid sites) or at the pore mouth regions (i.e., pore mouth acid sites formed with $\mathrm{Al}$ atom below the external surface) of 2D zeolites, which offer more space than those deeper inside the intracrystalline micropores of 3D zeolites. The 2D zeolites are usually made from exfoliation [18-24] and pillaring [6,15,25-30] of the 2D zeolite precursors that contain stacked zeolite nanosheets of one-to-two unit cell or smaller thickness. The catalytic tests have shown that the delaminated and pillared 2D zeolites have improved activity and lifetime with respect to their 3D microporous counterparts in processing bulky molecules [18,31-35]. 
Despite these practices in synthesis and catalytic tests of the unit-cell thick 2D zeolite catalysts, evaluation of acid site locations and the catalytic behaviors of acid sites at each location has not been extensively studied. The characteristic single- or near single-unit-cell thickness of the microporous domains in 2D zeolites enables the fraction of external surface and pore mouth acid sites becomes comparable to that in micropores [6,36]. The increased accessibility of acid sites to bulky molecules in pillared MWW (PMWW or MCM-36) $[9,37]$ and pillared MFI (PMFI) [15,26,36] zeolites has been verified by adsorption of 2,6-di-tertbutylpyridine (DTBP) base molecule. The multiple types of Brønsted acid sites with various strengths of 2D MFI zeolite were evidenced by the ${ }^{31} \mathrm{P}$ nuclear magnetic resonance (NMR) spectra of adsorbed trimethylphosphine oxide and tributylphosphine oxide, respectively [38]. The differentiation and quantification of external acid sites that sit on the external surface or at the pore mouth regions of 2D PMFI and PMWW zeolites, however, have not been explored in literature.

In the present work, we report the identification and quantification of acid sites on external surface and at pore mouth regions of unit-cell thick 2D PMFI and PMWW zeolites. PMWW is the first synthesized pillared 2D zeolite [23,27,37], which is derived from a layered precursor, MCM-22(P), reported by Mobil scientists in 1990s [39,40]. PMFI was reported by Ryoo and co-workers [26], which is synthesized by silica pillaring of the multilamellar MFI that is created by a diquaternary ammonium surfactant $\left(\mathrm{C}_{22} \mathrm{H}_{45}-\mathrm{N}^{+}\left(\mathrm{CH}_{3}\right)_{2}-\mathrm{C}_{6} \mathrm{H}_{12}-\mathrm{N}^{+}\left(\mathrm{CH}_{3}\right)_{2}-\mathrm{C}_{6} \mathrm{H}_{13}\left(\mathrm{Br}^{-}\right.\right.$ )$_{2}$ ) assisted hydrothermal crystallization process [16]. We implemented a combined dimethyl ether (DME) titration and methanol dehydration in the presence of DTBP or triphenylphosphine (TPP) base titrant, respectively, to quantify the fractions of acid sites on external surface, at pore mouth regions and in micropores of PMFI and PMWW zeolites. The same measurements were 
also carried out on PMFI and PMWW zeolites after their external surface acid sites were selectively passivated by the atomic layer deposition (ALD) of silica-species to further confirm the quantifications on fractions of external surface and pore mouth acid sites in these zeolites.

DME has a kinetic diameter of $4.7 \AA$ [41], which can access all the active acid sites in PMFI and PMWW zeolites. The difference in number of acid sites in zeolites before and after their external surface acid sites passivated by silica-species reflects the concentration of external surface acid sites. DTBP molecule is sterically bulky with a diameter $7.9 \AA$ [42] and has a strong base strength which can titrate acid sites on the external surface and at the pore mouth regions but cannot access those in the micropores of PMFI and PMWW zeolites [43-45]. Compared to DTBP, the TPP molecule is sterically bulkier with a diameter at $9.4 \AA$ [46] but has a weaker base strength $[47,48]$. It can solely access the acid sites on the external surface [49]. The decrease in methanol dehydration rate in the presence of DTBP or TPP titrant reflects the fractions of external surface and/or pore mouth acid sites in PMFI and PMWW zeolites. Additionally, the catalytic behavior of the external surface and pore mouth acid sites was evaluated by alkylation of benzyl alcohol in mesitylene with cumulative DTBP or TPP addition. The non-linear correlation between the decrease in alkylation rate and added DTBP or TPP quantity suggests that individual external surface or pore mouth acid site performed differently in the studied catalytic reaction.

\section{Experimental}

\subsection{Materials preparation}

PMFI was prepared by pillaring of a multilamellar MFI precursor following the method reported by $\mathrm{Na}$ et al. [26]. The multilamellar MFI precursor was synthesized using the method 
reported by Ryoo and co-workers [16]. PMWW zeolite was derived from the precursor, MCM22(P). The hydrothermal synthesis of MCM-22(P) was carried out by using the method described by Corma et al. [23]. The MCM-22(P) was swollen according to the method developed by Maheshwari et al. [27], followed by pillaring of the swollen material using the procedure reported by Barth et al. [37] to make PMWW zeolite. The as-synthesized PMFI and PMWW zeolites were ion-exchanged three times using $1 \mathrm{M}$ aqueous ammonium nitrate $\left(\mathrm{NH}_{4} \mathrm{NO}_{3}\right)$ (weight ratio of zeolite to $\mathrm{NH}_{4} \mathrm{NO}_{3}$ solution $=1: 10$ ) at $353 \mathrm{~K}$ for $12 \mathrm{~h}$, and subsequently, collected by centrifugation and washed with deionized (DI) water three times, and dried at $343 \mathrm{~K}$ overnight. All zeolite samples in their $\mathrm{NH}_{4}{ }^{+}$-form were treated in dry air $\left(100 \mathrm{~mL} \mathrm{~min}{ }^{-1}\right.$, Airgas $)$ by increasing the temperature from ambient temperature to $823 \mathrm{~K}$ at $0.03 \mathrm{~K} \mathrm{~s}^{-1}$ and holding at $823 \mathrm{~K}$ for $4 \mathrm{~h}$ to thermally decompose $\mathrm{NH}_{4}{ }^{+}$to $\mathrm{NH}_{3}$ and $\mathrm{H}^{+}$.

The ALD of silica species (ALD-Si) on PMFI and PMWW zeolites was performed as our previous report [36]. A viscous flow benchtop reactor (Gemstar-6, Arradiance) was used to carry out this experiment. $\mathrm{N}_{2}$ (Airgas, $99.999 \%$ purity) was used as a carrier gas $\left(50 \mathrm{~mL} \mathrm{~min}^{-1}\right)$ and further purified by a Supelco gas purifier (Sigma-Aldrich) before entering the reactor. $0.5 \mathrm{~g}$ of zeolite was uniformly spread onto a stainless steel tray with a mesh on top of it. The mesh prevented the spill of the sample and allowed access to the Si-precursor vapor in the ALD process. The ALD-Si was carried out by alternative exposure of zeolite sample to tris(dimethylamino)silane (TDMAS, Sigma-Aldrich, 99.999\%) and ozone at $573 \mathrm{~K}$ for $15 \mathrm{~s}$, followed by $\mathrm{N}_{2}$ purge for $200 \mathrm{~s}$ after each exposure. The resultant zeolite samples from ALD-Si modifications of PMFI and PMWW were denoted as Si-PMFI and Si-PMWW, respectively.

2.2 Quantification and differentiation of acid sites in PMFI and PMWW zeolites 


\subsubsection{Total number of acid sites determined by DME titration}

The total number of Brønsted acid sites in the PMFI and PMWW zeolite was measured via the DME titration. The Brønsted acid sites in zeolite participate in the reaction of DME with $\mathrm{H}^{+}$in two-to-one manner to form surface methyl groups, $\mathrm{CH}_{3} \mathrm{OCH}_{3}+2[\mathrm{SiO}(\mathrm{H}) \mathrm{Al}]=$ $2\left[\mathrm{SiO}\left(\mathrm{CH}_{3}\right) \mathrm{Al}\right]+\mathrm{H}_{2} \mathrm{O}$. The titration experiment was carried out in a tubular packed-bed quartz reactor $(10 \mathrm{~mm}$ inner diameter) under atmospheric pressure. The temperature of the reactor was held at $423 \mathrm{~K}$ by a resistively heated furnace (National Electric Furnace FA120 type). Catalyst temperature was measured using a K-type thermocouple touching the bottom of a well on the external surface of the quartz reactor. A mixture of DME, Ar and He (7.5\% DME, 22.5\% Ar, 70\% He, Airgas) flowed $\left(50 \mathrm{~cm}^{3} \mathrm{~s}^{-1}\right)$ through a sample loop $(0.250 \mathrm{~mL})$ and pulsed over zeolite samples in a He carrier stream $\left(50 \mathrm{~cm}^{3} \mathrm{~s}^{-1} ; 99.99 \%\right.$, Airgas) at 2 min intervals. Only $\mathrm{Ar}(\mathrm{m} / \mathrm{z}=40)$ was detected in reactor effluent from initial pulses of DME over the zeolite samples. DME (m/z = 45) was only detected in the reactor effluent after all $\mathrm{H}^{+}$sites had been replaced with $\mathrm{CH}_{3}$ groups. Thus, the number of $\mathrm{H}^{+}$sites was determined from the number of disappeared DME in the effluent. Details on the DME titration experimental setup and reaction conditions were described in our previous publications [30,31]. The same setup was used for the following methanol dehydration reactions in the presence of organic bases.

2.2.2 External surface and pore mouth acid sites determined by methanol dehydration in presence of organic base

To distinguish and quantify external surface, pore mouth and internal acid sites in PMFI and PMWW zeolites as well as Si-PMFI and Si-PMWW samples, methanol $\left(\mathrm{CH}_{3} \mathrm{OH}\right)$ dehydration in the presence of DTBP or TPP was measured at $433 \mathrm{~K}$. Typically, the liquid 
mixture of methanol (Fisher Scientific, 99.9\%) and organic base (either DTBP (Alfa Aesar, 98\% purity) or TPP (Alfa Aesar, 99+\% purity)) was introduced into a flowing He stream heated at 348 K using a syringe pump (NE 1000, New Era Pump System Inc.). The reactor effluent was sent via heated transfer lines (at $\sim 373 \mathrm{~K}$ ) to a mass spectrometer (MS, Ametek Proline). The methanol dehydration rate was reflected by the signal of dimethyl ether $(\mathrm{m} / \mathrm{z}=45)$ in MS spectra. The loss in methanol dehydration rate with DTBP or TPP addition reflects the accessibility of acid sites to DTBP or TPP molecules in PMFI and PMWW zeolites. The fraction of Brønsted acid sites on external surface $\left(f_{\mathrm{ext}, \mathrm{H}^{+}}\right)$of zeolites was determined by the degree of loss in $\mathrm{CH}_{3} \mathrm{OH}$ dehydration rate in the presence of TPP titrants. The sum of fractions of external surface and pore mouth acid sites $\left(f_{\text {sum }, \mathrm{H}^{+}}\right)$was indicated by the degree of loss in $\mathrm{CH}_{3} \mathrm{OH}$ dehydration rate in the presence of DTBP molecules. The fractions of pore mouth acid sites $\left(f_{\mathrm{pm}, \mathrm{H}^{+}}\right)$can be calculated by $f_{\mathrm{pm}, \mathrm{H}^{+}}=f_{\text {sum }, \mathrm{H}^{+}}-f_{\mathrm{ext}, \mathrm{H}^{+}}$. Together with the total number of acid sites quantified by the DME titration above, the number of external surface and pore mouth acid sites can then be evaluated by mutilation of $\mathrm{N}_{\text {tot }, \mathrm{H}^{+}}$with the corresponding fractions of acid sites in each location.

\subsection{Conversion of benzyl alcohol in mesitylene in the presence of DTBP or TPP titrant}

The liquid phase catalytic conversion of benzyl alcohol in mesitylene in the presence of organic bases was carried out in a three-necked round-bottom flask $(100 \mathrm{~mL})$ under atmospheric pressure and magnetic stirring, as reported in our previous work [30]. In a typical experiment, a desired amount of DTBP or TPP and $15 \mathrm{~mL}$ of mesitylene were added to the zeolite catalyst, which was maintained for $2.5 \mathrm{~h}$ at the required reaction temperature and stirring conditions. Afterwards, $0.25 \mathrm{~mL}$ of benzyl alcohol was added to above mixture. The moment of addition of benzyl alcohol was taken as the initial reaction time. Liquid samples were withdrawn at regular 
time intervals and analyzed by the gas chromatograph (Agilent 7890 A GC) equipped with a methyl-siloxane capillary column (HP-1, $50.0 \mathrm{~m} \times 320 \mu \mathrm{m} \times 0.52 \mu \mathrm{m})$ connected to a flame ionization detector. In the measurement, $1 \mu \mathrm{L}$ liquid sample was injected into the $\mathrm{GC}$ inlet at temperature of $523 \mathrm{~K}$ with a split ratio of 50 . The oven program was as follows: holding at $323 \mathrm{~K}$ for 5 mins, ramping to $473 \mathrm{~K}$ at a rate of $20 \mathrm{~K} \mathrm{~min}^{-1}$, holding at $473 \mathrm{~K}$ for 7 mins and then cooling down to $323 \mathrm{~K}$ within $\sim 5 \mathrm{~min}$. The $\mathrm{N}_{2}$ carrier gas flow rate in the column was set at 2.4 $\mathrm{mL} \min ^{-1}$. The temperature of FID detector was $573 \mathrm{~K}$. A $\mathrm{H}_{2}$ flow rate of $30 \mathrm{~mL} \mathrm{~min}{ }^{-1}$, air flow rate of $400 \mathrm{~mL} \mathrm{~min}^{-1}$, and $\mathrm{N}_{2}$ make-up flow rate of $22.8 \mathrm{~mL} \mathrm{~min}^{-1}$ was used in the FID detector.

\section{Results and discussion}

\subsection{Topological properties of 2D PMFI and PMWW zeolites}

Figure 1 shows the topological structures of PMFI and PMWW zeolites, viewed along the $\mathrm{b}$ - and c-axis direction, respectively. The PMFI zeolite (Figure 1(A)) consists of $\sim 1.5$ unitcell $(\sim 3.2 \mathrm{~nm})$ [21] thick microporous MFI layer and the inorganic silica pillars $(\sim 2.8 \mathrm{~nm}$ in height) between two zeolite nanosheet layers. The microporous MFI layer contains two interconnected 10-membered ring (MR) channel systems: one is straight running along the b-axis

direction $(5.3 \times 5.6 \AA)$ and the other one is zigzag running parallel to the a-axis direction $(5.1 \times$ 5.5 A). The PMFI contains mesopores created by the pillars sitting between MFI layers, parallel to the zigzag channels and perpendicular to the straight channels within the layers. Figure 1(B) shows the schematic structure of PMWW zeolite. Similarly, PMWW zeolite contains inorganic silica pillars with height of $\sim 1.8 \mathrm{~nm}$ and unit-cell thick $(\sim 2.5 \mathrm{~nm})$ microporous MWW layers [21]. Different from the microporous potion of PMFI structure, the microporous layer of PMWW contains two independent pore systems. One system is defined by sinusoidal 10-MR channels 
with dimensions of $4.1 \times 5.1 \AA$ and the other system consists of hourglass shaped pores (half of the supercages with dimensions of $7.1 \times 7.1 \times 18.1 \AA$ in MWW) delimited by 6-MR channels. The mesopores in PMWW was created by pillaring the MWW layers by $\mathrm{SiO}_{2}$, which directly talks to the hourglass shaped 12-MR pores in the microporous zeolite layers. The comparable dimensions on thickness of microporous layers and height of mesoporous galleries in either PMFI or PMWW zeolites suggest that a comparable number of acid sites stay on the external surface or at the pore mouth regions to that encapsulated in the micropores. The morphologies and textural properties of PMFI and PMWW zeolites have been studied by scanning and transmission electron microscopy and Ar adsorption-desorption measurements, respectively, which have been reported in our previous work [36].

\subsection{Structures of organic titrant molecules}

To identify the number of external surface and pore mouth acid sites in PMFI and PMWW zeolites, organic base molecules, DME, DTBP and TPP, respectively, were employed in the titration experiments. Figure $2(\mathrm{~A})-(\mathrm{C})$ shows the molecular structures and kinetic diameters of these three organic base molecules. As shown in Figure 2(A), DME has a kinetic diameter of $4.7 \AA[41]$, which is relatively small and thus is expected to access to the acid sites on external surface, at pore mouth regions and in micropores of PMFI and PMWW zeolites. On the contrary, DTBP (Figure 2(B)) has a kinetic diameter of $7.9 \AA$ and a strong base strength, which can titrate acid sites both on the external surface and at the pore mouth regions but cannot access those in the micropores of PMFI and PMWW zeolites. Compared to DTBP, the TPP molecule (Figure $2(\mathrm{C}))$ is sterically bulkier with a diameter at $9.4 \AA$, but has a weaker base strength[46]. It is expected to solely access the acid sites on the external surface. The passivation of external 
surface of PMFI and PMWW zeolites were done by ALD with TDMAS precursor (Figure 2(D)). The large size of TDMAS ( 6.7 $\AA$, determined with Avogadro software) has prevented its accessibility from the micropores of PMFI and PMWW zeolites, as indicated in our previous study [36].

\subsection{Quantification of external surface and pore mouth acid sites}

\subsubsection{Fractions of external surface acid sites determined by DME titration}

In DME titration experiments, the number of Brønsted acid sites $\left(\mathrm{H}^{+}\right)$was determined directly by their chemical reaction with DME to form methyl groups via sequential pulses of DME to replace $\mathrm{H}^{+}$sites with $\mathrm{CH}_{3}$ groups. Figure 3 shows that the titration profiles of PMFI, PMWW, Si-PMFI and Si-PMWW, respectively. DME and $\mathrm{CH}_{3} \mathrm{OH}$ were undetectable in the reactor effluent during the initial pulses on the zeolite samples, consistent with the fast and irreversible nature of this methylation reaction [50,51]. DME was detected in the effluent only after all protons were replaced by $\mathrm{CH}_{3}$ groups, while $\mathrm{CH}_{3} \mathrm{OH}$ was never detected in the effluent stream under the tested conditions, consistent with the work reported previously [50-52].

Table 1. Fractions of external surface acid sites $\left(f_{\text {ext, } \mathrm{H}^{+}}\right)$in PMFI and PMWW zeolites, respectively, determined by DME titration before and after ALD of $\mathrm{SiO}_{2}$ species.

\begin{tabular}{lcccc}
\hline Zeolite & Si/Al ratio & $\begin{array}{c}\mathrm{N}_{\text {tot, } \mathrm{H}^{+}}{ }^{a} \\
\left(\mu \mathrm{mol} \mathrm{H}^{+} \mathrm{g}^{-1}\right)\end{array}$ & $\begin{array}{c}\mathrm{N}_{\mathrm{ext}, \mathrm{H}^{+}}{ }^{(1) b} \\
\left(\mu \mathrm{mol} \mathrm{H} \mathrm{H}^{+1}\right)\end{array}$ & $\begin{array}{c}f_{\text {ext, } \mathrm{H}^{+}}{ }^{(1) c} \\
\text { PMFI }\end{array}$ \\
\hline Si-PMFI & 56 & 185 & 59 & 32 \\
PMWW & 57 & 126 & - & - \\
Si-PMWW & 32 & 330 & 91 & 28 \\
\hline
\end{tabular}


${ }^{a}$ Total amount of Bronsted acid sites measured by DME titration; ${ }^{b}$ Calculated by subtracting the total amount of acid sites in ALD-treated zeolite from that in its parent zeolite; ${ }^{c}$ Fraction of external surface acid sites, calculated by $f_{\text {ext }, H^{+}}{ }^{(1)}=$

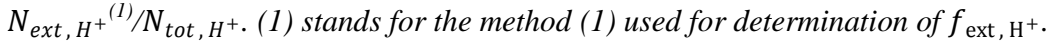

Table 1 summarizes the total number of acid sites $\left(N_{\text {tot, } \mathrm{H}^{+}}\right)$in PMFI, PMWW, Si-PMFI and Si-PMWW zeolites, respectively, which are calculated from the DME titration profiles shown in Figure 3. The PMFI and PMWW zeolites contain 185 and $330 \mu \mathrm{mol} \mathrm{\textrm {H } ^ { + }} \mathrm{g}^{-1}$, respectively. The Si-PMFI and Si-PMWW zeolites, however, consist of 126 and $239 \mu \mathrm{mol} \mathrm{H}^{+} \mathrm{g}^{-1}$

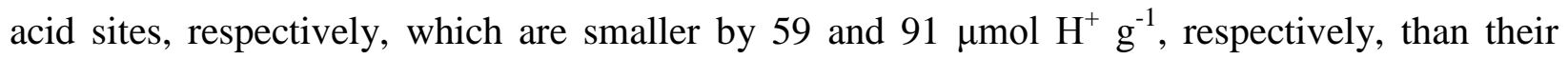
parent pillared zeolites. The decrease in the number of acid sites in Si-PMFI and Si-PMWW zeolites was caused by the coverage of external surface acid sites in PMFI and PMWW zeolites by $\mathrm{SiO}_{2}$ species from the ALD modifications.

As indicated in Figure 2(D), the molecular size of the $\mathrm{SiO}_{2}$ precursor, TDMAS, is $6.7 \AA$, which can diffuse freely in the mesopores of both PMFI and PMWW zeolites to reach acid sites on external surface of zeolites, given the size of mesopores in PMFI $(\sim 2.8 \mathrm{~nm})$ and PMWW $(\sim 1.8 \mathrm{~nm})$ zeolites. However, the steric constraint of the bulky TDMAS prevents its access to acid sites in micropores of PMFI and PMWW zeolites. Therefore, the external surface acid sites is expected to be deactivated upon ALD passivation of PMFI and PMWW zeolites. The elemental compositions (represented by Si/Al ratios) of PMFI and PMWW zeolites and their derivatives after ALD modification were measured by inductively coupled plasma optical emission spectrometry in our previous study[36], which is repeatedly shown in Table 1 (column 2) for comparison purpose. For both PMFI and PMWW zeolites, the ALD modification resulted in a very slight increase in Si/Al ratios. The weight gains of PMFI and PMWW zeolites due to ALD of $\mathrm{SiO}_{2}$-species are calculated to be $1.7 \mathrm{wt} \%$ and $3.8 \mathrm{wt} \%$, respectively, in Si-PMFI and SiPMWW zeolites. The mismatch between the slight weight gain for both PMFI and PMWW 
zeolites and the significant drop in total amount of acid sites in both Si-PMFI and Si-PMWW zeolites indicates that the decrease of total acid sites was mainly resulted from the passivation of external surface acid sites via ALD treatment instead of the dilution effect. Therefore, the comparative analyses of DME titrations of acid sites over PMFI and PMWW zeolites before and after ALD treatment, respectively, is a feasible approach to quantify the fractions of external surface acid sites. As calculated in Table 1, the fractions of external surface acid sites in PMFI and PMWW zeolites are $32 \%$ and $28 \%$, respectively.

3.3.2 Fractions of external surface and pore mouth acid sites determined by methanol dehydration in presence of DTBP or TPP titrant, respectively

To investigate further on the distributions of acid sites on the external surface or at the pore mouth regions of PMFI and PMWW zeolites, a series of titration experiments with TPP or DTBP organic base were conducted during methanol dehydration reactions. Figure 4 shows methanol dehydration rates as a function of cumulative DTBP (Figure 4(A)) or TPP (Figure 4(B)) titrant addition on the pillared zeolites, respectively. Titration with DTBP or TPP over all zeolites initially resulted in a sharp decrease in methanol dehydration rates. At saturation of DTBP or TPP titrants, methanol dehydration maintained different residual rates over the PMFI and PMWW zeolites, suggesting that the bulky DTBP or TPP molecules have limited and different accessibility to Brønsted acid sites in PMFI and PMWW zeolites $[2,43,44,49,53]$. For the same zeolite, apparently, the residual methanol dehydration rate was higher upon TPP saturation than that of DTBP saturation, suggesting that TPP has less accessibility to acid sites in both PMFI and PMWW zeolites. 
DTBP base molecules can only titrate Brønsted acid sites because the steric hindrance around its $\mathrm{N}$-atom prevents its coordination to Lewis acid sites [44,50,54]. Additionally, its bulkiness and strong base strength determine that DTBP is not capable of accessing acid sites in micropores of PMWW and PMFI zeolites, but can coordinate with acid sites at pore mouth regions and on external surface $[44,55,56]$. Compared to DTBP, TPP is sterically bulkier and has a weaker base strength $[47,48]$ and can solely access the acid sites on the external surface. Both DTBP and TPP have been reported to coordinate with the Brønsted acid sites in zeolites at 1:1 ratio $[44,45,49,55,57]$. Therefore, the degree in loss of methanol dehydration rate upon DTBP saturation reflected the fractions of the sum of acid sites on the external surface and at pore mouth regions $\left(f_{\text {sum }, \mathrm{H}^{+}}\right)$. The degree in loss of methanol dehydration rate upon TPP saturation indicated the fraction of external surface acid sites $\left(f_{\text {ext }, \mathrm{H}^{+}}\right)$. The fraction of acid sites at pore mouth regions, $f_{\mathrm{pm}, \mathrm{H}^{+}}$, can be evaluated by the calculation, $f_{\mathrm{pm}, \mathrm{H}^{+}}=f_{\text {sum }, \mathrm{H}^{+}}-f_{\mathrm{ext}, \mathrm{H}^{+}}$.

Table 2 lists the fractions of external surface and pore mouth acid sites in both PMFI and PMWW zeolites. The sum of fractions of external surface and pore mouth acid sites are $37 \%$ and 67\%, respectively, in PMFI and PMWW zeolites. The fractions of external surface acid sites are $32 \%$ and 37\%, respectively. The fraction of external surface acid sites of PMFI zeolite is consistent with the number determined from the DME titration of acid sites in PMFI before and after ALD treatment. The fraction of external surface acid sites of PMWW zeolite, however, is slightly higher than that measured from the DME titration of acid sites in PMWW before and after ALD treatment. The differences in mechanisms of both quantification methods as well as the differences in sizes and configurations of TDMAS and TPP probe molecules could contribute to the different fractions of external surface acid sites in PMWW zeolite. Hence, the fractions of pore mouth acid sites in PMFI and PMWW zeolites can be calculated to be 5\% and 30\%, 
respectively. Eventually, the fractions of internal acid sites, $f_{\mathrm{int}, \mathrm{H}^{+}}$, are calculated to be $63 \%$ and 33\%, respectively, in PMFI and PMWW zeolites (Table 2).

Table 2. Fractions of external surface $\left(f_{\text {ext, } \mathrm{H}^{+}}\right)$and pore mouth acid sites $\left(f_{\mathrm{pm}, \mathrm{H}^{+}}\right)$in PMFI and PMWW zeolites determined by DTBP and TPP titrations in methanol dehydration reaction.

\begin{tabular}{lcccc}
\hline Zeolite & $\begin{array}{c}f_{\text {sum }, \mathrm{H}^{+}}{ }^{a} \\
(\%)\end{array}$ & $\begin{array}{r}f_{\text {ext, } \mathrm{H}^{+}}\left({ }^{(2) b}\right. \\
(\%)\end{array}$ & $\begin{array}{c}f_{\mathrm{pm}, \mathrm{H}^{+}}{ }^{(2) c} \\
(\%)\end{array}$ & $\begin{array}{c}f_{\mathrm{int}, \mathrm{H}^{+}}{ }^{d} \\
(\%)\end{array}$ \\
\hline PMFI & 37 & 32 & 5 & 63 \\
PMWW & 67 & 37 & 30 & 33
\end{tabular}

${ }^{a}$ Sum of fractions of external surface and pore mouth acid sites determined by DTBP titration during methanol dehydration reaction; ${ }^{b}$ Fraction of external surface acid sites determined by TPP titration during methanol dehydration reaction; ${ }^{c}$ Fraction of pore mouth acid sites calculated by $f_{p m, H^{+}}{ }^{(2)}=f_{\text {sum }, H^{+-}} f_{\text {ext }, H^{+}}{ }^{(2)}$. (2) stands for method (2) used for determination of fractions of external surface and pore mouth acid sites, ${ }^{d}$ Fraction of internal acid sites calculated by $f_{\text {int }, H^{+}}=1-f_{\text {sum }}, H^{+}$.

3.3.3 Fractions of pore mouth acid sites determined by methanol dehydration over Si-PMFI and Si-PMWW in presence of DTBP titrant

It has been reported that silylation of zeolites with tetraethyl orthosilicate (TEOS) preferentially deactivates acid sites on the external surface or at the pore mouth regions [58,59]. As discussed in Section 3.3.1, passivation of external surface acid sites of PMFI and PMWW zeolites was achieved by ALD with TDMAS precursor. Our previous report [36] also indicates that the mesoporosity of Si-PMFI and Si-PMWW decreased significantly from that of PMFI and PMWW zeolites but the microporosity remained almost intact. All these results suggest that acid sites at pore mouth regions and in micropores of Si-PMFI and Si-PMWW zeolites are active in reactions. By taking the advantage of Si-PMFI and Si-PMWW zeolites, the fractions of pore mouth acid sites in both zeolites can be quantified via methanol dehydration reaction in the presence of DTBP titrant. 
As shown in Figure 5, methanol dehydration rates decreased monotonically with cumulative addition of DTBP. The degrees in loss of methanol dehydration rate upon DTBP saturation were $12 \%$ and $45 \%$, respectively, for Si-PMFI and Si-PMWW zeolites (Table 3). Since the external surface acid sites were passivated by $\mathrm{SiO}_{2}$ species in Si-PMFI and Si-PMWW zeolites, the degrees in loss of methanol dehydration rates reflect only the fractions of pore mouth acid sites. Given the total amount of acid sites shown in Table 1, the amount of pore

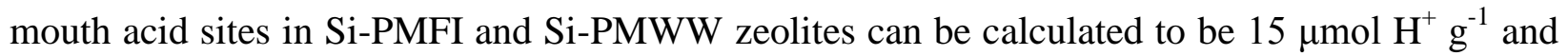
$108 \mu \mathrm{mol} \mathrm{H}^{+} \mathrm{g}^{-1}$, respectively. Because the pore mouth acid sites remained intact in the ALD treatment, the amount of pore mouth acid sites in PMFI and PMWW zeolites equals to that of SiPMFI and Si-PMWW zeolites, namely $15 \mu \mathrm{mol} \mathrm{H}^{+} \mathrm{g}^{-1}$ and $108 \mu \mathrm{mol} \mathrm{\textrm {H } ^ { + }} \mathrm{g}^{-1}$, respectively. Therefore, the fractions of pore mouth acid sites $\left(f_{\mathrm{pm}, \mathrm{H}^{+}}{ }^{(3)}\right)$ in PMFI and PMWW zeolites can be calculated by $f_{\mathrm{pm}, \mathrm{H}^{+}}{ }^{(3)}=\mathrm{N}_{\mathrm{pm}, \mathrm{H}^{+}} / \mathrm{N}_{\mathrm{tot}, \mathrm{H}^{+}}$, which equal to $8 \%$ and $32 \%$, respectively.

Table 3. Fractions of pore mouth acid sites $\left(f_{\mathrm{pm}, \mathrm{H}^{+}}\right)$in PMFI and PMWW zeolites determined by DTBP titration of Si-PMFI and Si-MWW zeolites in methanol dehydration reaction.

\begin{tabular}{|c|c|c|c|c|c|c|c|}
\hline Zeolite & $\begin{array}{c}f_{\mathrm{pm}, \mathrm{H}^{+}}{ }^{a} \\
(\%)\end{array}$ & $\begin{array}{c}\mathrm{N}_{\mathrm{pm}, \mathrm{H}^{+}}{ }^{b} \\
\left(\mathrm{~mol} \mathrm{H}^{+} \mathrm{g}^{-1}\right)\end{array}$ & Zeolite & $\begin{array}{c}\mathrm{N}_{\mathrm{pm}, \mathrm{H}^{+}{ }^{c}} \\
\left(\mathrm{~mol} \mathrm{H}{ }^{+} \mathrm{g}^{-1}\right)\end{array}$ & $\begin{array}{c}f_{\mathrm{pm}, \mathrm{H}^{+}}(3) d \\
(\%)\end{array}$ & $\begin{array}{c}f_{\mathrm{pm}, \mathrm{H}^{+}}{ }^{e} \\
(\%)\end{array}$ & $\begin{array}{c}f_{\text {ext }, \mathrm{H}^{+}}{ }^{f} \\
(\%)\end{array}$ \\
\hline Si-PMFI & 12 & 15 & PMFI & 15 & 8 & 6 & 32 \\
\hline Si-PMWW & 45 & 108 & PMWW & 108 & 32 & 31 & 33 \\
\hline
\end{tabular}

Up to now, we have conducted three different approaches to quantify the fractions of external surface and pore mouth acid sites in PMFI and PMWW zeolites. The first method, DME titration of acid sites in PMFI and PMWW zeolites before and after ALD treatment, directly 
calculated the fractions of external surface acid sites to be $32 \%$ and $28 \%$, respectively. The third method, methanol dehydration with cumulative poisoning of acid sites by DTBP over Si-PMFI and Si-PMWW zeolites showed that the fractions of pore mouth acid sites are $8 \%$ and $32 \%$, respectively. The second method by methanol dehydration over PMFI and PMWW zeolites with cumulative addition of DTBP or TPP differentiated and quantified the fractions of acid sites on the external surface and at pore mouth regions. Overall, the fractions of external surface or pore mouth acid sites were both identified twice by these three different approaches. If we take average of these measurement results, PMFI has $32 \%$ external surface, $6 \%$ pore mouth and $62 \%$ internal acid sites. Similarly, PMWW has 33\% external surface, $31 \%$ pore mouth and $36 \%$ internal acid sites, as shown in Table 3.

3.4 Catalytic behavior of acid sites on external surface and at pore mouth regions

In order to study the role of acid sites within different local environments, i.e. external surface and pore mouth regions, in the catalytic reaction, the liquid phase parallel catalytic conversion of benzyl alcohol in mesitylene (etherification to dibenzyl ether and alkylation to 1,3,5-trimethyl-2-benzylbenzene) was used as the probe reaction. The apparent rate constant of the alkylation reaction was evaluated at $348 \mathrm{~K}$, with less than $10 \%$ conversion of benzyl alcohol, under rigorous agitation, and in excess amount of mesitylene (molar ratio of mesitylene to benzyl alcohol $=45: 1)$ to eliminate the effect of catalyst deactivation and external surface mass transfer limitation, and reaction that converts dibenzyl ether to 1,3,5-trimethyl-2-benzylbenzene [6,15]. It has been reported that alkylation occurs only on the external surface and pore mouth acid sites of PMFI and PMWW zeolites due to the bulkiness of mesitylene compared to 10-MR micropores $[6,15]$. Since the primary focus of the present study is to evaluate the catalytic behaviors of 
external surface and pore mouth acid sites, only the alkylation results were discussed in the present study. In addition, in order to understand the catalytic behavior of the individual external surface and pore mouth acid sites, the external surface and pore mouth acid sites of PMFI and PMWW zeolites were purposely and progressively poisoned by addition of DTBP or TPP base titrants in the alkylation reaction.

By applying pseudo-first order reaction model on the reaction data, the alkylation rate constant, $k_{\text {alk }}$, can be readily analyzed. The model for the alkylation reaction is: $\ln \frac{C_{\mathrm{A}}^{0}}{C_{\mathrm{A}}}=k_{\mathrm{alk}}\left(N_{\mathrm{ext}, \mathrm{H}^{+}}+N_{\mathrm{pm}, \mathrm{H}^{+}}\right)(1-x \%)(1+\alpha) t$, where $C_{A}^{0}$ is the initial benzyl alcohol concentration in solution $\left(\mathrm{mol} \mathrm{L}^{-1}\right), C_{A}$ is benzyl alcohol concentration in solution $(\mathrm{mol} \mathrm{L}-1), N_{\mathrm{ext}}, \mathrm{H}^{+}\left(\mathrm{mol} \mathrm{H}^{+}\right)$ and $N_{\mathrm{pm}, \mathrm{H}^{+}}\left(\mathrm{mol} \mathrm{H} \mathrm{H}^{+}\right)$are the moles of external surface and pore mouth acid sites, respectively, of the catalyst present in the batch reactor (Table 2$), x(\%)$ is the percentage of external surface and pore mouth acid sites that were poisoned by base titrant, $\alpha$ is the product selectivity $(\alpha=$ $2 \mathrm{C}_{\mathrm{E}} / \mathrm{C}_{\mathrm{C}}, \mathrm{C}_{\mathrm{E}}$ and $\mathrm{C}_{\mathrm{C}}$ are the concentrations of dibenzyl ether and 1,3,5-trimethyl-2-benzylbenzene in solution ( $\left.\mathrm{mol} \mathrm{L}^{-1}\right)$, respectively), and $t$ is the reaction time (s), respectively.

Figure 6 demonstrates that the alkylation rate constant per acid site (external surface and pore mouth acid sites, i.e., ext + pm acid sites) with continuous addition of DTBP or TPP to progressively poison portions of these external surface and/or pore mouth acid sites. For the reaction over PMFI zeolite, a prompt drop in alkylation activity (>90\%) per acid site with a small fraction of external surface and pore mouth acid sites $(\sim 10 \%)$ poisoned by DTBP and then the slow drop (only $\sim 10 \%$ ) in activity with $\sim 90 \%$ of external surface and pore mouth acid sites poisoned by DTBP imply that some external surface and pore mouth acid sites are very active while others are insignificant in enabling the alkylation reaction (Figure 6(A)). This result 
suggests that the individual external surface or pore mouth acid site in PMFI performs differently in alkylation reaction. Different from PMFI zeolite, the alkylation reaction rate constant per ext+pm acid site in PMWW drops slowly upon cumulative DTBP addition into the reaction

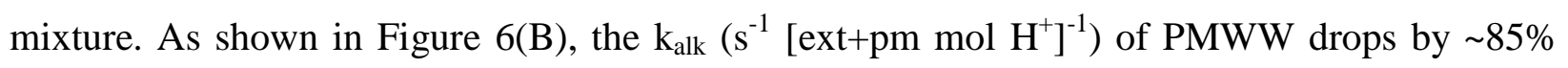
when $\sim 40 \%$ of external surface and pore mouth acid sites were poisoned by DTBP. The further addition of DTBP to poison the ext+pm acid sites from $40 \%$ to $100 \%$ caused $\sim 15 \%$ decrease in the alkylation rate constant. The significant difference in $\mathrm{k}_{\mathrm{alk}}$ decrease when different portions of acid sites in PMFI or PMWW zeolite were poisoned by DTBP might result from different acid strengths of these acid sites, as evidenced by the fact that the basic DTBP prefers to poison highly active acid sites [45]. The different acid strengths of these acid sites may be correlated to their locations, as quantified in this study. Apparently, PMFI and PMWW zeolites have different pore topologies, as discussed in section 3.1, and as consequences, the alkylation on both zeolites have different responses when the external surface and pore mouth acid sites were progressively deactivated by DTBP titrant. It should be noted that the alkylation reaction disappeared when $100 \%$ external surface and pore mouth acid sites were occupied by DTBP titrants, which reflects that the alkylation reaction solely occurred on the external surface and pore mouth acid sites of PMFI and PMWW zeolites.

Figure 6 (C) and (D) show the changes in alkylation rate constant of PMFI and PMWW zeolites when the external surface acid sites were progressively poisoned by cumulative addition of TPP titrants into the reaction mixture. For PMFI zeolite, the initial addition of TPP ( 40\% of

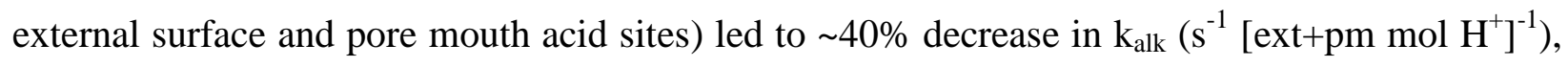
as illustrated in Figure 6(C). The further addition of TPP into the reactant solution, however, did not influence the catalytic capability of individual acid site. Similarly, the changes in catalytic 
behavior of individual external surface or pore mouth acid sites in PMWW zeolite upon TPP progressively poisoning (Figure 6(D)) follow the trend of PMFI zeolite, in which a significant catalytic activity remained upon TPP saturation. Since the bulky configuration and less basicity of TPP led to the sole poisoning of acid sites on the external surface, the remaining activity could be assigned to the contribution from pore mouth acid sites in both PMFI and PMWW zeolites. The initial decrease followed by a plateau in $\mathrm{k}_{\mathrm{alk}}\left(\mathrm{s}^{-1}[\mathrm{ext}+\mathrm{pm} \mathrm{mol} \mathrm{H}]^{-1}\right)$ in both Figure $6(\mathrm{C})$ and (D) demonstrates that external surface and pore mouth acid sites have different reaction rate constants in the alkylation reaction.

\section{Conclusions}

The quantification of acid sites on external surface and at pore mouth regions in PMFI and PMWW zeolites was conducted via three approaches: DME titration of acid sites before and after the external surface of zeolites passivated by $\mathrm{SiO}_{2}$-species, methanol dehydration over PMFI and PMWW with cumulative addition of TPP or DTBP titrants, and methanol dehydration over Si-PMFI and Si-PMWW with cumulative addition of DTBP titrants, respectively. The fractions of external surface or pore mouth acid sites identified by these methods consistently show that PMFI and PMWW have 32\% and 33\% external surface acid sites, and $6 \%$ and $31 \%$ pore mouth acid sites, respectively. The catalytic behavior of individual external surface or pore mouth acid site was evaluated by alkylation of benzyl alcohol in mesitylene with cumulative addition of DTBP or TPP titrants. The rapid decrease with small fraction of acid sites poisoned and then a slow decrease with the remaining acid sites poisoned in the alkylation rate constant per external surface and pore mouth acid site in both PMFI and PMWW zeolites suggest that the individual acid site performs significantly different in the catalytic reaction. Additionally, the 
cumulative poisoning experiment with TPP titrants suggests that external surface and pore mouth acid sites have different rate constants in the alkylation reaction, reflected by the residual activity of both PMFI and PMWW zeolites after the external surface acid sites were fully poisoned by TPP titrants.

\section{Acknowledgements}

This work was supported by the National Science Foundation [NSF-CBET 1264599 and 1351384]. Yiqing Wu thanks for the Hulka Energy Research Fellowship from University of Maryland Energy Research Center (UMERC) to support his research. The authors would like to thank Dr. Yu Lei and Mr. Lu Zheng for the help with preparation of Si-PMFI and Si-PMWW zeolite samples using ALD method.

\section{References}

[1] F.J. Liu, T. Willhammar, L. Wang, L.F. Zhu, Q. Sun, X.J. Meng, W. Carrillo-Cabrera, X.D. Zou, F.S. Xiao, J. Am. Chem. Soc. 134 (2012) 4557-4560.

[2] K. Kim, R. Ryoo, H.D. Jang, M. Choi, J. Catal. 288 (2012) 115-123.

[3] W. Park, D. Yu, K. Na, K.E. Jelfs, B. Slater, Y. Sakamoto, R. Ryoo, Chem. Mater. 23 (2011) 5131-5137.

[4] C.S. Cundy, P.A. Cox, Chem. Rev. 103 (2003) 663-701.

[5] M.E. Davis, Nature 417 (2002) 813-821.

[6] D.X. Liu, X.Y. Zhang, A. Bhan, M. Tsapatsis, Micropor. Mesopor. Mater. 200 (2014) 287290.

[7] J. Perez-Ramirez, C.H. Christensen, K. Egeblad, C.H. Christensen, J.C. Groen, Chem. Soc. Rev. 37 (2008) 2530-2542.

[8] A. Corma, Chem. Rev. 97 (1997) 2373-2419.

[9] D.X. Liu, A. Bhan, M. Tsapatsis, S. Al Hashimi, Acs. Catal. 1 (2011) 7-17.

[10] W.J. Roth, B. Gil, W. Makowski, B. Marszalek, P. Eliasova, Chem. Soc. Rev. 45 (2016) 3400-3438.

[11] M.V. Opanasenko, W.J. Roth, J. Cejka, Catal. Sci. Technol. 6 (2016) 2467-2484.

[12] W.J. Roth, P. Nachtigall, R.E. Morris, J. Cejka, Chem. Rev. 114 (2014) 4807-4837.

[13] K. Moller, T. Bein, Chem. Soc. Rev. 42 (2013) 3689-3707.

[14] M. Tsapatsis, W. Fan, Chemcatchem 2 (2010) 246-248. 
[15] X.Y. Zhang, D.X. Liu, D.D. Xu, S. Asahina, K.A. Cychosz, K.V. Agrawal, Y. Al Wahedi, A. Bhan, S. Al Hashimi, O. Terasaki, M. Thommes, M. Tsapatsis, Science 336 (2012) 16841687.

[16] M. Choi, K. Na, J. Kim, Y. Sakamoto, O. Terasaki, R. Ryoo, Nature 461 (2009) 246-U120.

[17] P. Eliasova, M. Opanasenko, P.S. Wheatley, M. Shamzhy, M. Mazur, P. Nachtigall, W.J. Roth, R.E. Morris, J. Cejka, Chem. Soc. Rev. 44 (2015) 7177-7206.

[18] R.C. Runnehaum, X.Y. Ouyang, J.A. Edsinga, T. Rea, I. Arslan, S.J. Hwang, S.I. Zones, A. Katz, Acs. Catal. 4 (2014) 2364-2368.

[19] X.Y. Ouyang, S.J. Hwang, R.C. Runnebaum, D. Xie, Y.J. Wanglee, T. Rea, S.I. Zones, A. Katz, J. Am. Chem. Soc. 136 (2014) 1449-1461.

[20] I. Ogino, E.A. Eilertsen, S.J. Hwang, T. Rea, D. Xie, X.Y. Ouyang, S.I. Zones, A. Katz, Chem. Mater. 25 (2013) 1502-1509.

[21] K. Varoon, X.Y. Zhang, B. Elyassi, D.D. Brewer, M. Gettel, S. Kumar, J.A. Lee, S. Maheshwari, A. Mittal, C.Y. Sung, M. Cococcioni, L.F. Francis, A.V. McCormick, K.A. Mkhoyan, M. Tsapatsis, Science 334 (2011) 72-75.

[22] I. Ogino, M.M. Nigra, S.J. Hwang, J.M. Ha, T. Rea, S.I. Zones, A. Katz, J. Am. Chem. Soc. 133 (2011) 3288-3291.

[23] A. Corma, V. Fornes, S.B. Pergher, T.L.M. Maesen, J.G. Buglass, Nature 396 (1998) 353356.

[24] H.Y. Luo, V.K. Michaelis, S. Hodges, R.G. Griffin, Y. Roman-Leshkov, Chem. Sci. 6 (2015) 6320-6324.

[25] B.Y. Liu, C. Wattanaprayoon, S.C. Oh, L. Emdadi, D.X. Liu, Chem. Mater. 27 (2015) 14791487.

[26] K. Na, M. Choi, W. Park, Y. Sakamoto, O. Terasaki, R. Ryoo, J. Am. Chem. Soc. 132 (2010) 4169-4177.

[27] S. Maheshwari, E. Jordan, S. Kumar, F.S. Bates, R.L. Penn, D.F. Shantz, M. Tsapatsis, J. Am. Chem. Soc. 130 (2008) 1507-1516.

[28] F. Jin, S. Huang, S. Cheng, Y. Wu, C.-C. Chang, Y.-W. Huang, Catal. Sci. Technol. 5 (2015) 3007-3016.

[29] A.G. Machoke, I.Y. Knoke, S. Lopez-Orozco, M. Schmiele, T. Selvam, V.R.R. Marthala, E. Spiecker, T. Unruh, M. Hartmann, W. Schwieger, Micropor. Mesopor. Mater. 190 (2014) 324333.

[30] Y. Wu, L. Emdadi, Z. Wang, W. Fan, D. Liu, Appl. Catal. Gen. 470 (2014) 344-354.

[31] Y.Q. Wu, L. Emdadi, S.C. Oh, M. Sakbodin, D.X. Liu, J. Catal. 323 (2015) 100-111.

[32] L.M. Ren, Q. Guo, P. Kumar, M. Orazov, D.D. Xu, S.M. Alhassan, K.A. Mkhoyan, M.E. Davis, M. Tsapatsis, Angew. Chem. Int. Edit. 54 (2015) 10848-10851.

[33] S.H. Cha, J. Lee, J. Shin, S.B. Hong, Top. Catal. 58 (2015) 537-544.

[34] E. Verheyen, C. Jo, M. Kurttepeli, G. Vanbutsele, E. Gobechiya, T.I. Koranyi, S. Bals, G. Van Tendeloo, R. Ryoo, C.E.A. Kirschhock, J.A. Martens, J. Catal. 300 (2013) 70-80.

[35] A.J.J. Koekkoek, W. Kim, V. Degirmenci, H. Xin, R. Ryoo, E.J.M. Hensen, J. Catal. 299 (2013) 81-89.

[36] Y. Wu, Z. Lu, L. Emdadi, S.C. Oh, J. Wang, Y. Lei, H. Chen, D.T. Tran, I.C. Lee, D. Liu, J. Catal. 337 (2016) 177-187.

[37] J.O. Barth, A. Jentys, J. Kornatowski, J.A. Lercher, Chem. Mater. 16 (2004) 724-730.

[38] Y. Seo, K. Cho, Y. Jung, R. Ryoo, Acs. Catal. 3 (2013) 713-720.

[39] C.T. Kresge, Roth, W.J., Simmons, K.G., Vartuli, J.C., US Patent 5229341, 1993. 
[40] C.T. Kresge, Roth, W.J., Simmons, K.G., Vartuli, J.C., WO Patent 92/011935, 1992.

[41] J.B. Lad, Y.T. Makkawi, Chem. Eng. J. 256 (2014) 335-346.

[42] V.V. Ordomsky, V.Y. Murzin, Y.V. Monakhova, Y.V. Zubavichus, E.E. Knyazeva, N.S.

Nesterenko, I.I. Ivanova, Micropor. Mesopor. Mater. 105 (2007) 101-110.

[43] L. Emdadi, S.C. Oh, Y. Wu, S.N. Oliaee, Y. Diao, G. Zhu, D. Liu, J. Catal. 335 (2016) 165174.

[44] K. Gora-Marek, K. Tarach, M. Choi, J. Phys. Chem. C 118 (2014) 12266-12274.

[45] A. Corma, V. Fornes, L. Forni, F. Marquez, J. Martinez-Triguero, D. Moscotti, J. Catal. 179 (1998) 451-458.

[46] C.S.H. Chen, S.E. Schramm, Microporous. Mater. 7 (1996) 125-132.

[47] B. Hu, I.D. Gay, Langmuir 15 (1999) 477-481.

[48] B. Hu, I.D. Gay, Langmuir 11 (1995) 3845-3847.

[49] Y. Wang, J. Zhuang, G. Yang, D. Zhou, D. Ma, X. Han, X. Bao, J. Phys. Chem. B 108 (2004) 1386-1391.

[50] R. Gounder, A.J. Jones, R.T. Carr, E. Iglesia, J. Catal. 286 (2012) 214-223.

[51] P. Cheung, A. Bhan, G.J. Sunley, E. Iglesia, Angew. Chem. Int. Edit. 45 (2006) 1617-1620.

[52] P. Cheung, A. Bhan, G.J. Sunley, D.J. Law, E. Iglesia, J. Catal. 245 (2007) 110-123.

[53] J.F. Denayer, A.R. Ocakoglu, W. Huybrechts, J.A. Martens, J.W. Thybaut, G.B. Marin, G.V. Baron, Chem. Commun. (2003) 1880-1881.

[54] C.D. Baertsch, K.T. Komala, Y.H. Chua, E. Iglesia, J. Catal. 205 (2002) 44-57.

[55] D. Fărcaşiu, R. Leu, A. Corma, J. Phys. Chem. B 106 (2002) 928-932.

[56] B.J. Xu, H.Y. Li, W.M. Hua, Y.H. Yue, Z. Gao, J. Catal. 240 (2006) 31-38.

[57] D. Farcasiu, M. Lezcano, P. Lukinskas, D.H. Waldeck, J. Phys. Chem. A 104 (2000) 51905196.

[58] S.R. Zheng, H.R. Heydenrych, A. Jentys, J.A. Lercher, J. Phys. Chem. B 106 (2002) 95529558.

[59] R.W. Weber, K.P. Möller, C.T. O'Connor, Micropor. Mesopor. Mater. 35-36 (2000) 533543. 


\section{List of Figures}

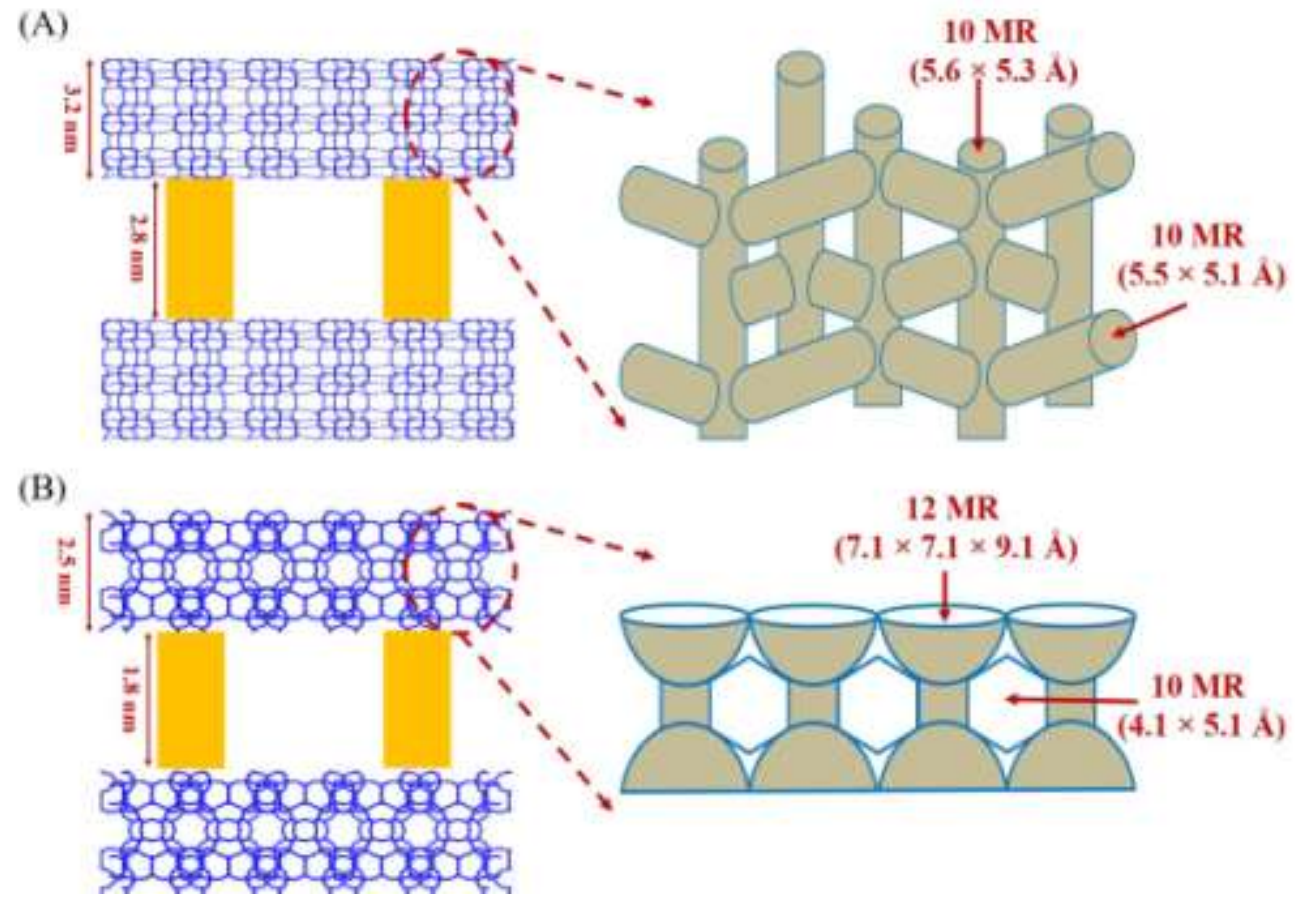

Figure 1. Schematic pictures showing the topological structure of PMFI (A) and PMWW (B) zeolites. 
(A)

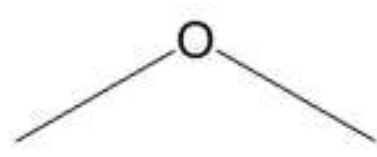

$(\sim 4.7 \AA)$

(C)

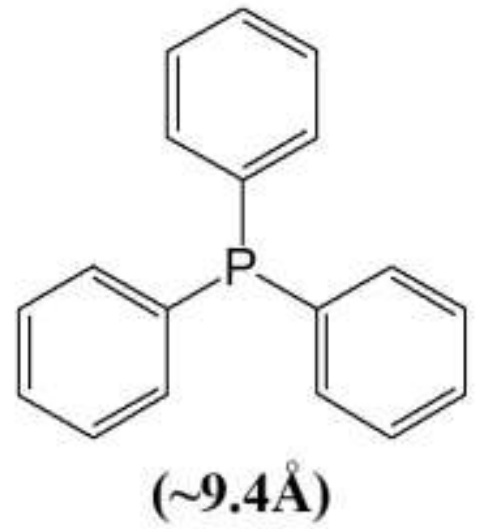

(B)

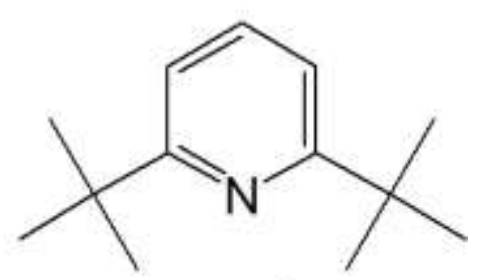

( 7.9A)

(D)

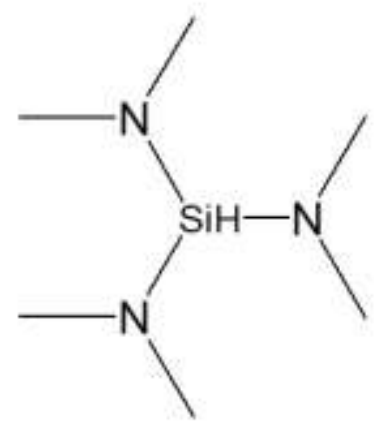

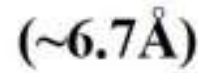

Figure 2. Molecular structure and kinetic diameter of DME (A), DTBP (B), TPP (C) and TDMAS (D) molecules, respectively. 

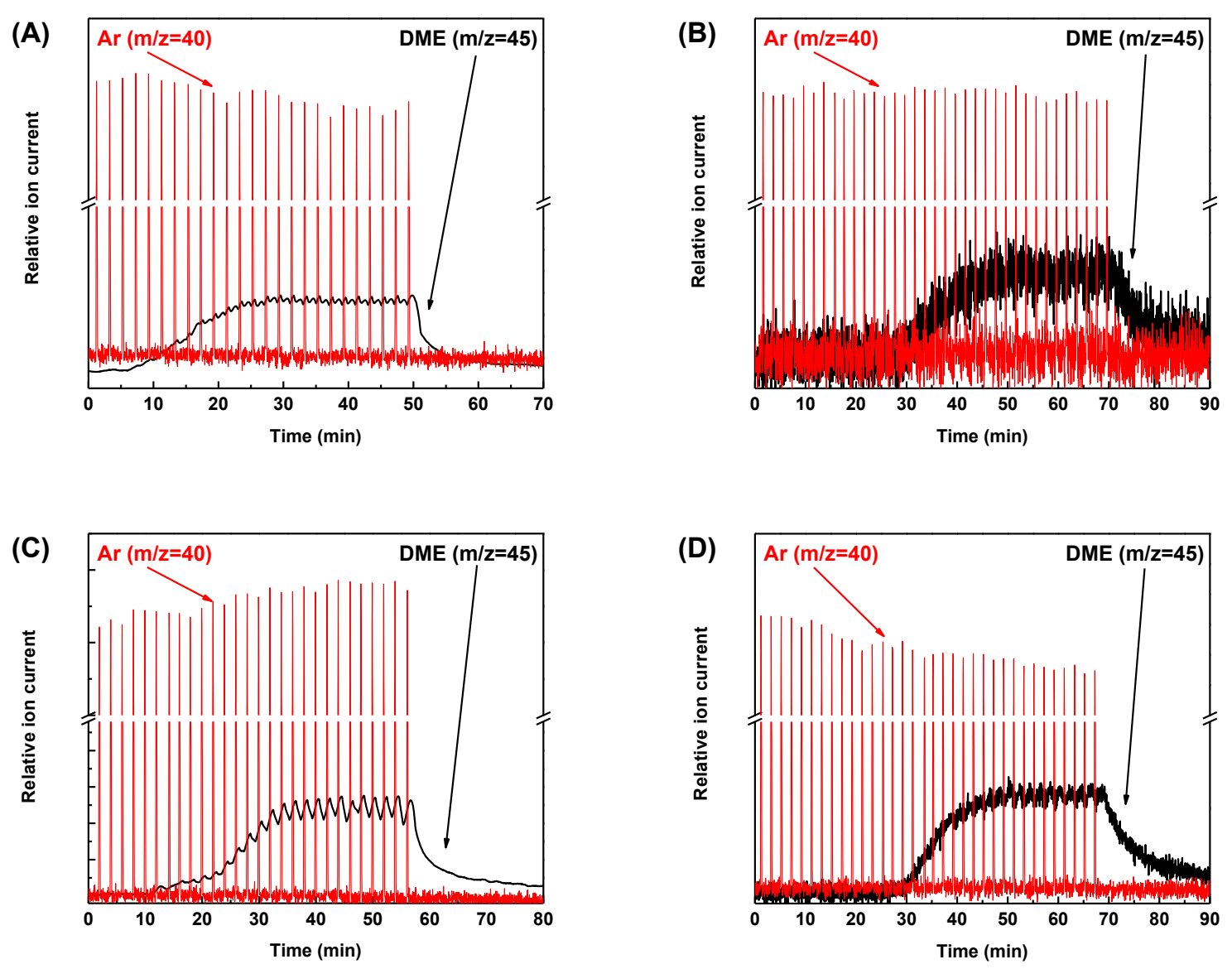

Figure 3. Mass spectra signals of $\mathrm{DME}(\mathrm{m} / \mathrm{z}=45$, thick black line) and $\mathrm{Ar}(\mathrm{m} / \mathrm{z}=40$, thin red line) during DME/Ar pulses on PMFI (A), PMWW (B), Si-PMFI (C) and Si-PMWW (D), respectively (measured at $423 \mathrm{~K}$ ). 

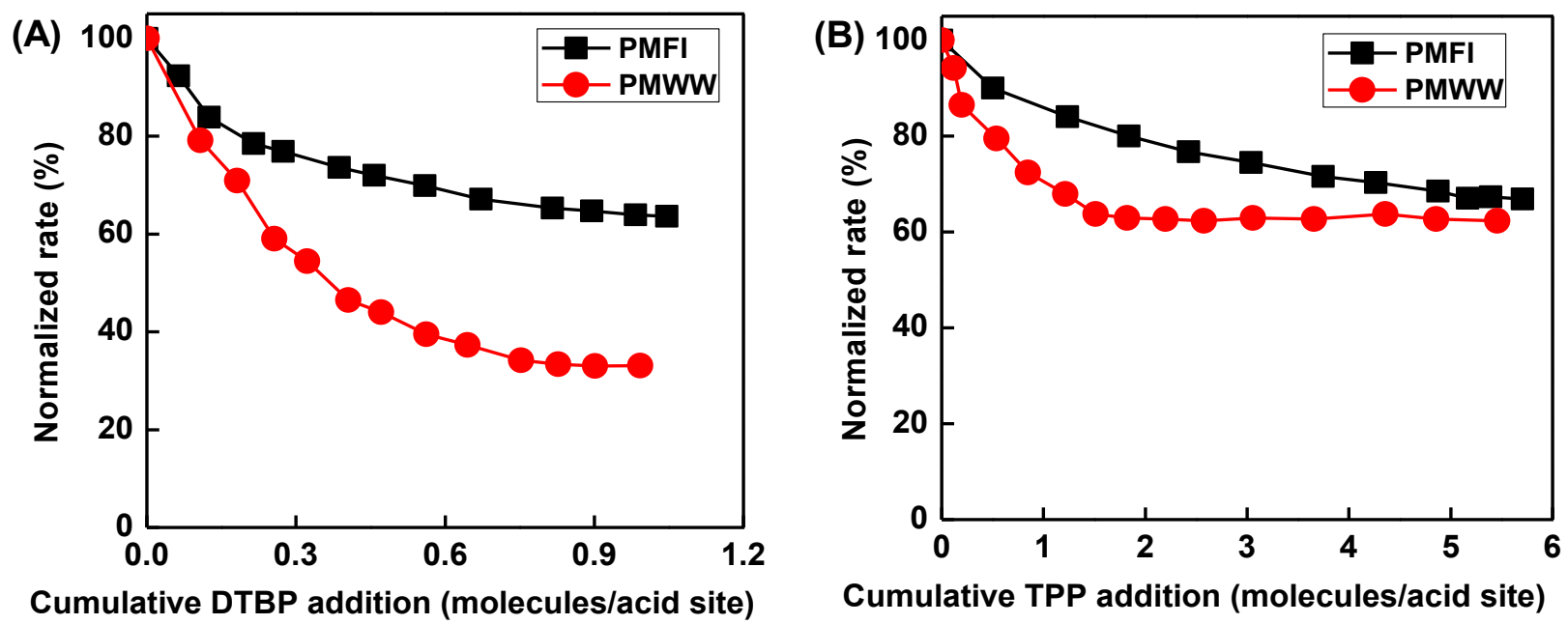

Figure 4. DTBP (A) and TPP (B) base titration of acid sites on PMFI and PMWW zeolites during methanol dehydration reaction.

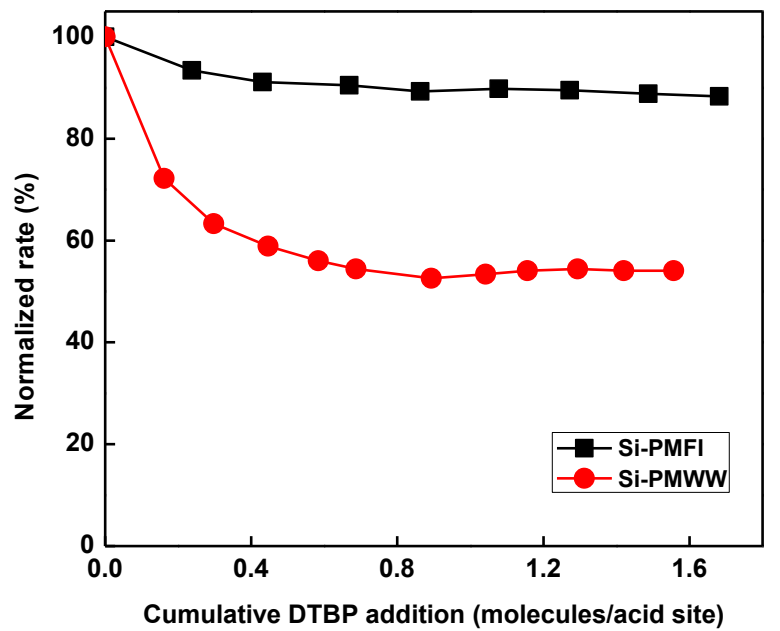

Figure 5. DTBP base titration of acid sites on Si-PMFI and Si-PMWW zeolites during methanol dehydration reaction. 

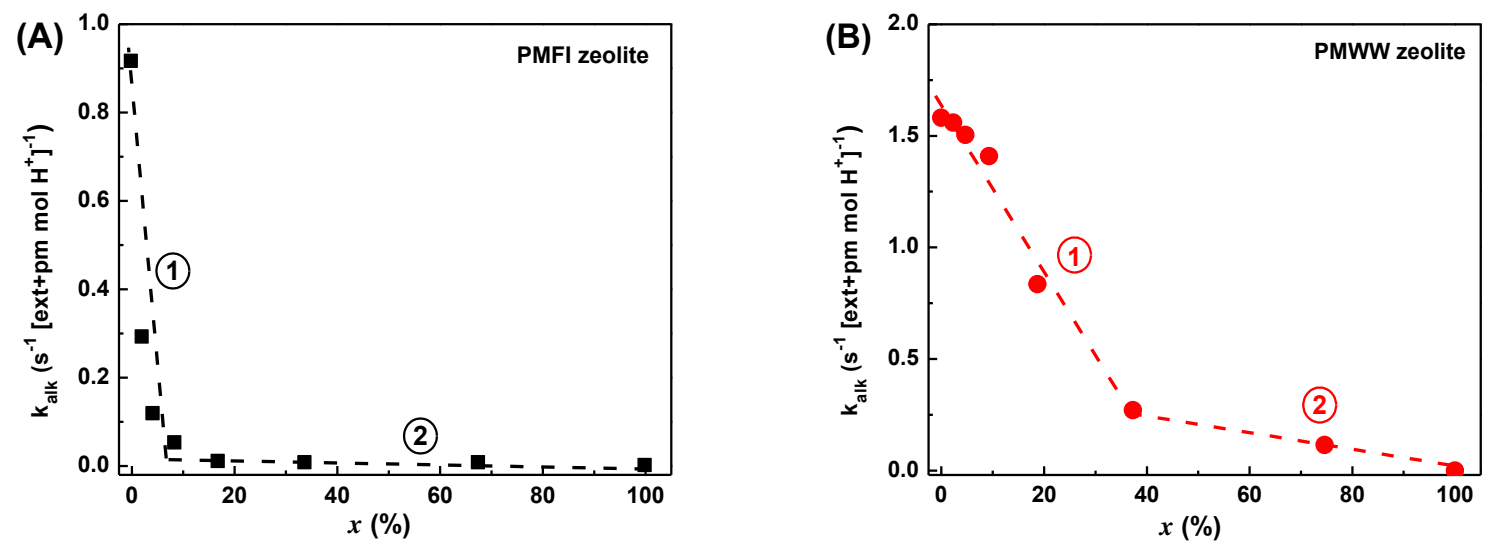

Cumulative DTBP addition (molecules/(ext+pm) acid site)

Cumulative DTBP addition (molecules/(ext+pm) acid site)
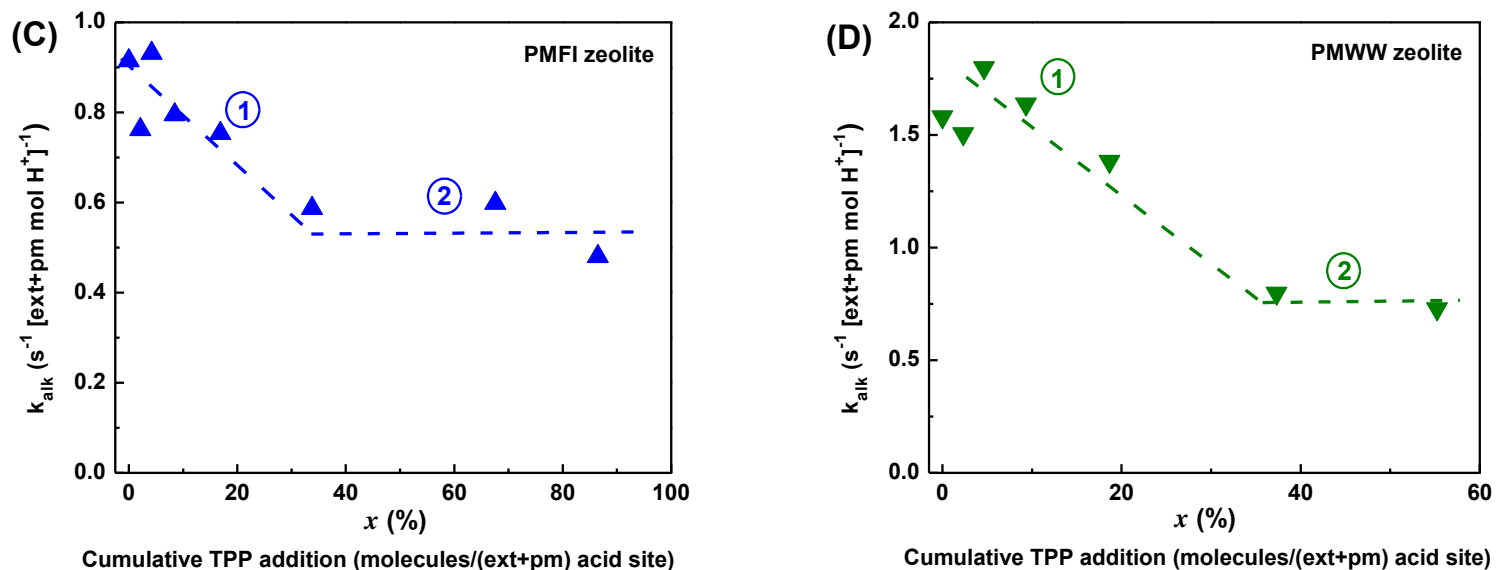

Figure 6. Alkylation rate constant per external surface and pore mouth acid site with cumulative addition of DTBP on PMFI (A) and PMWW (B) or with cumulative addition of TPP on PMFI (C) and PMWW (D) in the alkylation of mesitylene with benzyl alcohol. (x (\%) represents the percentage of active external surface and pore mouth acid sites poisoned by DTBP or TPP). (1) and (2) show two distinct segments in each plot, indicating two different catalytic behavior of external surface and/or pore mouth acid sites upon cumulative poisoning in alkylation reaction) 

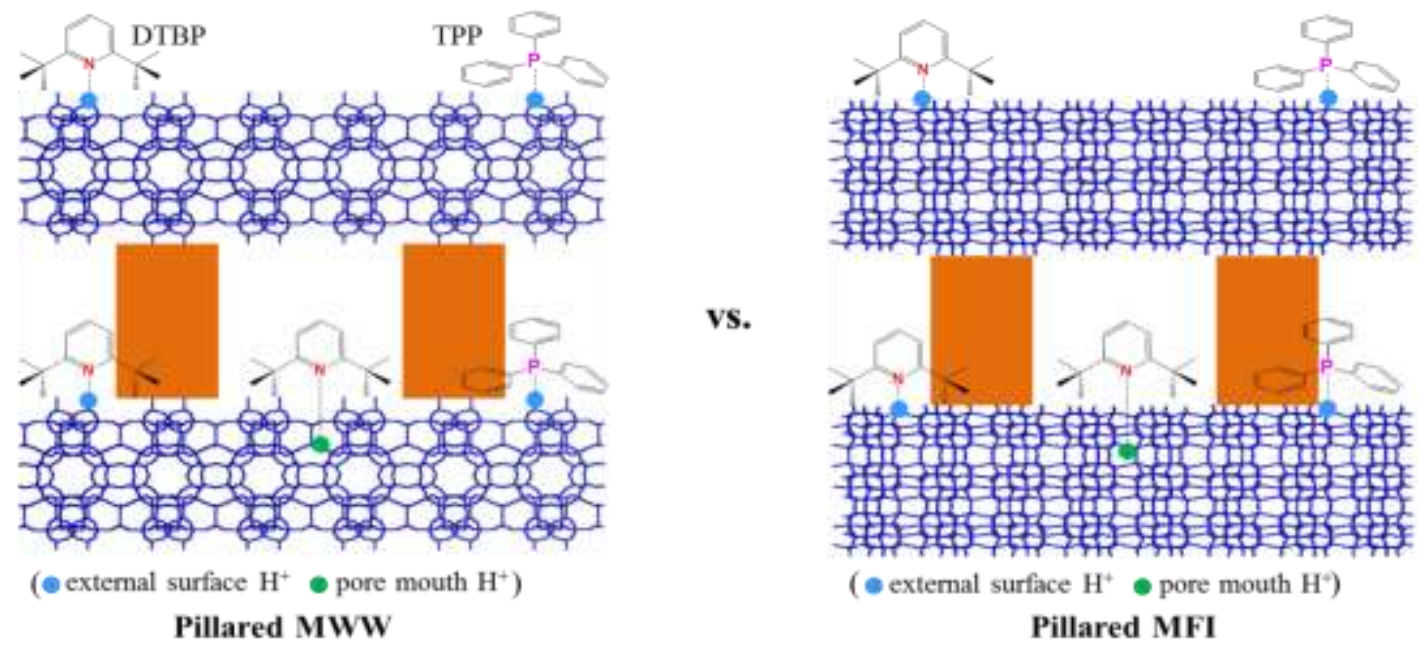